\title{
Interferência entre plantas daninhas e a cultura: alterações no metabolismo secundário
}

\section{Interference between weeds and crop: changes in secondary metabolism}

\author{
Ana Paula Rockenbach ${ }^{1 *}$, Mauro Antônio Rizzardi², Anderson Luis Nunes ${ }^{3}$, \\ Mario Antonio Bianchi ${ }^{4,5}$, Andréia Caverzan ${ }^{1}$, Theodoro Schneider ${ }^{1}$
}

\begin{abstract}
Resumo - Os metabólitos secundários garantem a sobrevivência das plantas em situações adversas. As plantas alteram sua constituição bioquímica a partir do metabolismo primário em resposta à mudanças no ambiente. A produção de metabólitos secundários mitiga os efeitos decorrentes do estresse permitindo o desenvolvimento da planta em situações não ideais. Compostos aleloquímicos são exemplos de metabólitos secundários produzidos por plantas em situação de interferência interespecífica. Quando em estresse por competição, as plantas possuem a capacidade de liberar compostos no ambiente a fim de sinalizar a presença ou inibir o crescimento de plantas vizinhas. As respostas no metabolismo secundário das culturas decorrentes da competição com plantas daninhas alteram a composição química da espécie, resultando em alterações no desenvolvimento e no rendimento. A aplicação de herbicidas também é fonte de alteração no metabolismo secundário pela interrupção de rotas, seja pelo acúmulo de ácidos constituintes ou a formação de compostos não desejados. A revisão atual tem como objetivo mostrar o estado da arte das relações de interferência entre plantas daninhas e as culturas sobre as alterações no metabolismo secundário.
\end{abstract}

Palavras-chave: ácido chiquímico, alelopatia, competição, metabólitos secundários

\begin{abstract}
Secondary metabolites ensure the survival of plants in adverse situations. Plants change their biochemical constitution from the primary metabolism in response to changes in the environment. The production of secondary metabolites mitigates the effects of stress, allowing the plant development in non-ideal situations. Allelochemical compounds are examples of secondary metabolites produced by plants in situations of interspecific interference. When in competition stress, plants have the ability to release compounds into the environment in order to signal the presence or inhibit the growth of neighboring plants. Secondary metabolism responses of crops resulting from competition with weeds alter the chemical composition of the species, resulting in changes in development and yield. The application of herbicides is also an alteration source in the secondary

Recebido: Fevereiro 06, 2017. Aceito: Janeiro 11, 2018.

${ }^{1}$ Programa de Pós-graduação em Agronomia, Faculdade de Agronomia e Medicina Veterinária, Universidade de Passo Fundo - UPF, BR 285, Bairro São José, CEP 99052-900, Passo Fundo, RS, Brasil.

E-mail: anapagronomia@yahoo.com.br; acaverzan@hotmail.com; theodoroschneider@hotmail.com

${ }^{2}$ Faculdade de Agronomia e Medicina Veterinária, Universidade de Passo Fundo - UPF, Passo Fundo, RS, Brasil. E-mail: rizzardi@upf.br

${ }^{3}$ Instituto Federal do Rio Grande do Sul, Campus Sertão, Sertão, RS, Brasil. E-mail: anderson.nunes@sertao.ifrs.edu.br

${ }^{4}$ Universidade de Cruz Alta - UNICRUZ, Cruz Alta, RS, Brasil. E-mail: mario.bianchi@ccgl.com.br

${ }^{5}$ Cooperativa Central Gaúcha LTDA, Cruz Alta, RS, Brasil.
\end{abstract}


metabolism by the interruption of routes, either by the accumulation of constituent acids or the formation of unwanted compounds. The current review aims to show the art state of interference relationships between weeds and crops on changes in secondary metabolism.

Keywords: shikimic acid, allelopathy, competition, secondary metabolites

\section{Introdução}

Os elementos do metabolismo primário possuem função estrutural, plástica e de armazenamento de energia. Exemplos destes são os lipídios, carboidratos, proteínas e ácidos nucléicos. Os elementos que não tem participação direta no metabolismo essencial, e que apresentam distribuição restrita no reino vegetal, constituem o metabolismo secundário. Acredita-se que a variedade e a complexidade das moléculas originadas do metabolismo secundário das plantas são resultantes de milhões de anos de evolução, como estratégias químicas a fim de possibilitar sua sobrevivência como forma de proteção e resistência às intempéries do clima e predadores, por exemplo (Viegas-Junior et al., 2006).

As plantas ao responderem à estímulos, alteram rapidamente seus compostos bioquímicos, e esta rápida indução de produção de metabólitos secundários beneficia a defesa ao estresse e as favorecem no seguimento do seu desenvolvimento (Metlen et al., 2008). Os metabólitos secundários têm funções ecológicas específicas como, atrativos ou repelentes para insetos e outros animais fornecendo as plantas sabores chamativos ou repulsivos, pigmentos que fornecem cor para flores e frutos, atração de insetos polinizadores para reprodução e animais para consumir os frutos e dispersar as sementes (Garcia e Carril, 2009; Delory et al., 2016).

As alterações no metabolismo secundário podem ser originadas da interferência das plantas daninhas e da aplicação de herbicidas. O sorgoleone é um exemplo de metabólito secundário, uma benzoquinona lipídica liberada para o solo a partir dos tricomas das raízes do sorgo com potencial alelopático (Santos et al., 2012). Alterações no conteúdo de metabólitos das culturas foram detectados quando em competição com plantas daninhas (Langaro et al., 2011; Afifi e Swanton,
2012; Silva et al., 2014; Gal et al., 2015). Alterações nas rotas metabólicas das espécies oriundas de aplicação de herbicidas, modificam o metabolismo secundário das plantas (Chuah et al., 2016; Marchezan et al., 2017). Atualmente os trabalhos que consideram interferência de plantas daninhas, avaliam além das alterações já conhecidas causadas pela interferência, as modificações sobre o metabolismo secundário das espécies. Bem como, as alterações metabólicas causadas pela aplicação de herbicidas sobre as culturas para o controle de plantas daninhas.

A revisão atual tem como objetivo mostrar o estado da arte das relações de interferência entre plantas daninhas e as culturas sobre as alterações no metabolismo secundário.

\section{Metabolismo secundário}

As plantas possuem compostos químicos que são constantemente alterados em resposta aos fatores abióticos e bióticos do meio ambiente, assim, tornam-se essenciais para a sobrevivência e aptidão reprodutiva de uma espécie dentro do seu ambiente natural (Chezem e Clay, 2016). Os metabólitos secundários são exemplos de compostos que são produzidos em resposta a diversos fatores ambientais. Estes apresentam distribuição restrita, alguns são exclusivos a uma espécie ou a um grupo de espécies relacionadas (Metlen et al., 2008; Taiz e Zeiger, 2013).

A formação dos metabólitos secundários se dá por vias de biossíntese que derivam do metabolismo primário do carbono (Garcia e Carril, 2009), via os intermediários principais, o ácido chiquímico e o acetato. Os metabólitos originados do ácido chiquímico são aminoácidos aromáticos precursores da maioria dos metabólitos secundários aromáticos. Os derivados do acetato, são classificados de acordo com a via metabólica seguida: derivados do acetato via ciclo do ácido cítrico; derivados do 
acetato via mevalonato; e produtos de condensação do acetato. Alguns metabólitos são resultantes da combinação de uma unidade de ácido chiquímico e uma ou mais unidades de acetato ou derivados (Taiz e Zeiger, 2013).

Os compostos fenólicos são originados do ácido chiquímico, e os pertencentes ao metabolismo secundário têm uma vasta diversidade de estruturas, possuem propriedade antioxidante, e muitos são constituintes de óleos voláteis (Silva et al., 2010). Além disso, agem na defesa da planta contra herbívoros e patógenos, outros têm função como atrativo de polinizadores ou dispersores de frutos (Taiz e Zeiger, 2013).

Os alcaloides também são originados do ácido chiquímico, e constituem um vasto grupo de metabólitos com grande diversidade estrutural. Alguns são considerados tóxicos aos animais, como exemplo, os alcaloides pirrolizidínicos encontrados no gênero Senecio e Crotalaria para ruminantes e equinos (Lucena et al., 2010). Outros possuem potencial alelopático, como a solasonina, um alcaloide glicosilado encontrado em frutos de Solanum crinitum, que inibe significativamente o comprimento da raiz principal de plântulas de alface (Alves et al., 2003).

Alguns terpenos derivados do acetato pela via mevalonato, são considerados metabólitos primários, como as giberelinas, os carotenoides e o ácido abcísico. Entretanto, a maior parte dos terpenos são metabólitos secundários relacionados com a defesa vegetal, como exemplo os terpenos que são tóxicos e inibem insetos e mamíferos herbívoros, ou ainda os que são óleos essenciais e apresentam propriedades como repelentes de insetos (Taiz e Zeiger, 2013).

\section{Fatores abióticos que influenciam no conteúdo de metabólitos secundários}

Pouco se sabe sobre o impacto do estresse ocasionado pela interferência entre plantas no metabolismo secundário (Rivoal et al., 2011; Silva et al., 2014). Entretanto, são conhecidos os efeitos de estresses abióticos sobre a produção de metabólitos secundários. Alguns destes estresses abióticos podem ser gerados ou intensificados durante a competição interespecífica entre plantas. Neste sentido, nesta seção discutir-se-á como os principais estresses abióticos oriundos ou intensificados em uma situação de competição interespecífica influenciam na produção de metabólitos secundários.

A água disponível na solução do solo é um dos principais recursos disputados na competição interespecífica (Radosevich et al., 2007). Segundo os autores, as espécies de plantas daninhas possuem raízes mais eficientes na absorção de água e geram estresse hídrico nas culturas. A presença das plantas daninhas tiririca (Cyperus rotundus), caruru (Amaranthus spinosus), trapoeraba (Commelina benghalensis) e capim-milhã (Digitaria bicornis) em competição com a cultura do meloeiro (Cucumis melo) aumentaram o consumo de água durante o ciclo total da cultura em 136 e $163 \mathrm{~m}^{3} \mathrm{ha}^{-1}$, nos sistemas de semeadura direta e convencional, respectivamente (Teofilo et al., 2012). A soja ao competir com as espécies daninhas picão (Bidens pilosa) e braquiária (Urochloa brizantha) reduziu a eficiência do uso da água, demonstrando efeito mais pronunciado ao competir com braquiária, assim, é necessário maior quantidade de água transpirada para produção de matéria seca (Ferreira et al., 2015).

A disponibilidade hídrica influencia todos os processos fisiológicos dos vegetais, e conseguinte, o estresse hídrico têm consequências significativas na produção de metabólitos secundários, sendo dependente do grau de estresse e do período em que ocorre (Gobbo-Neto e Lopes, 2007). As concentrações de metabólitos secundários, como os compostos fenólicos (Sampaio et al., 2011) e os terpenos (Selmar e Kleinwächter, 2013) aumentam em plantas sob condições de seca. Os carotenoides, conhecidos também como tetraterpenos, são oriundos dos terpenos e são responsáveis pela mitigação dos efeitos do estresse oxidativo. Assim, herbicidas inibidores do Fotossistema I e da enzima PROTOX, que 
controlam as plantas daninhas por meio da peroxidação da membrana plasmática causada pela formação de espécies reativas de oxigênio (EROs), podem ter sua eficiência comprometida, quando aplicados em plantas daninhas sobre estresse hídrico. Neste sentido, o estresse hídrico causado pela interferência influencia no metabolismo secundário da planta.

A presença ou ausência de luz é outro fator ambiental que influencia seletivamente o nível de certos compostos fenólicos (Sampaio et al., 2011; Rechner et al., 2016). As diferenças de qualidade e quantidade de luz em um ambiente de competição são percebidas pelas plantas através de alterações no vermelho/vermelho extremo (Delory et al., 2016). Essa percepção pode levar a uma resposta de defesa e ativar o metabolismo secundário (Broz et al., 2010). Assim, ao perceber a luz refletida, a cultura estiola a haste, suprime ramificações, modifica a partição de biomassa (Green-Tracewicz et al., 2012), e altera a morfologia das raízes (Gal et al., 2015).

Muitos metabólitos secundários estão envolvidos com a pigmentação das plantas e também com a proteção contra excesso luminoso. Ao ocorrer a reflexão de radiação de onda curta, raios UV-B, a produção de metabólitos secundários é ativada, pois esses raios induzem vias de resposta a estresses (Rechner et al., 2016). As flavonas, os flavonóis e as antocianinas fazem parte do grupo dos flavonoides, e agem na proteção das células contra o excesso de radiação UV-B. Da mesma forma, os carotenoides, um tipo de terpeno, são pigmentos responsáveis pela dissipação de energia. $\mathrm{O}$ excesso de energia luminosa pode ser ocasionado como resposta a aplicação de herbicidas. Portanto, a competição pela luz ocasionada pela presença das plantas daninhas e a aplicação de herbicidas nos cultivos, influencia na produção de metabólitos secundários.

A competição por nutrientes é influenciada pelo teor de água no solo, pela cultivar, espécie daninha e pelo grau de competição (Cury et al., 2012). Híbridos de milho reduziram o conteúdo relativo de micro e macronutrientes devido a interferência com Brachiaria brizantha, onde verificou-se conteúdo relativo total médio inferior a $30 \%$ para $\mathrm{K}, \mathrm{Ca}, \mathrm{S}$, $\mathrm{Zn}, \mathrm{Fe}$ e Cu e de 30 a $35 \%$ para N, P, Mg e Mn em relação a ausência de interferência (Cury et al., 2012). As plantas daninhas apresentam elevada capacidade de extrair nutrientes do solo quando em competição com outra espécie, sendo variável conforme a planta daninha e a espécie cultivada (Medeiros et al., 2016).

A soja em competição com picão preto (Bidens pilosa) e braquiária (Urochloa decubens) reduziu em 60, 59 e $61 \%$, e 45, 68 e 74\% os níveis de P, N e K respectivamente (Fialho et al., 2016). Macro e micronutrientes influenciam no tipo e na concentração de metabólitos secundários (Gobbo-Neto e Lopes, 2007; Sampaio et al., 2011). A distribuição dos metabólitos na inflorescência e nas partes radiculares de margaridão (Tithonia diversifolia) foi afetada principalmente pela variação de nutrientes do solo como Ca, Mg, P, K e Cu (Sampaio et al., 2016). Assim sendo, os nutrientes disponíveis para as espécies influenciam na quantidade e qualidade de metabólitos secundários.

\section{Alterações no metabolismo secundário decorrentes da interferência com plantas daninhas}

Relações de interferência de competição e alelopatia entre espécies ativam os mecanismos de defesa nas plantas, alterando assim, o metabolismo secundário. Uma das respostas é o aumento da produção de aleloquímicos, que são metabólitos secundários produzidos e liberados no ambiente pelas plantas, e afetam o crescimento e desenvolvimento das plantas receptoras (Shah et al., 2016). Muitas culturas tem o potencial de produzir, liberar e exsudar diferentes aleloquímicos para a rizosfera e atmosfera, e inibem o crescimento de plantas daninhas e de outras culturas nas suas imediações (Shah et al., 2016). Por exemplo, a inibição do crescimento de plantas daninhas quando em competição com o trigo, através da liberação de 
compostos alelopáticos pelas raízes da cultura (Li et al., 2016).

Inúmeras plantas daninhas possuem o potencial de produção e liberação de aleloquímicos no ambiente. Como o capim annoni (Eragrostis plana Nees), que foi introduzido no Brasil acidentalmente, e tornou-se uma importante planta daninha, pois seu crescimento e desenvolvimento em áreas agrícolas não permite o sucesso de outras espécies. Seu potencial alelopático foi verificado sobre milho, aveia branca, azevém, trevo vermelho e cornichão, onde o aumento da concentração do extrato aquoso de folhas de capim annoni até $100 \%$, reduziu o índice de velocidade de germinação, o comprimento da parte aérea e do sistema radicular de todas as espécies (Fiorenza et al., 2016).

Compostos como lipídios, fenóis, ligninas e alcaloides foram encontrados nas folhas do capim annoni, já nas raízes identificaram-se os mesmos compostos, e ainda o amido (Favaretto et al., 2015). O efeito alelopático frente a outras espécies, possivelmente, seja pela presença dos metabólitos secundários dos grupos dos compostos fenólicos, flavonoides e taninos. Ao qualificá-los encontraram-se os compostos fenólicos ácido gálico, ácido elágico, ácido cafeico e ácido clorogênico, os flavonoides quercetina e rutina, e os taninos epicatequina e catequina (Fiorenza et al., 2016). A concentração e o potencial alelopático podem ser alterados de acordo com a dose de nitrogênio e o estádio de coleta da planta. Plantas adubadas com $200 \mathrm{~kg}$ de nitrogênio apresentaram a maior concentração de ácidos cafeico, ferúlico, vanílico e p-cumárico quando comparados a dose de $100 \mathrm{~kg}$, bem como a maior concentração destes ácidos foi encontrada no estádio reprodutivo do capim annoni (Cecchin, et al., 2017).

O potencial alelopático da espécie pode variar de acordo com o órgão da planta utilizado para a extração, a dose de nitrogênio e o estádio fenológico. $\mathrm{O}$ extrato aquoso de folhas de capim anonni sobre trevo branco apresenta maior potencial alelopático quando comparado ao extrato de raízes (Favaretto et al., 2011). Logo, para doses de nitrogênio e estádio fenológico do capim annoni, as doses de 100 e 200 kg e o estádio reprodutivo aumentam a inibição da germinação e reduzem o índice de velocidade de germinação (Cecchin, et al., 2017).

Uma espécie com alto potencial alelopático é o sorgo, que é utilizado como planta forrageira e como cobertura de solo. Esta espécie possui em sua composição química, o aleloquímico sorgoleone. O sorgoleone é um composto altamente lipofílico, constituído por um ácido graxo poliinsaturado com um anel de benzoquinona (Dayan et al., 2003). Este aleloquímico afeta a fotossíntese, a respiração e a atividade da enzima p-hidroxifenilpiruvato desidrogenase a qual é necessária para a síntese de plastoquinona (Meazza et al., 2002). É produzido e liberado principalmente por pêlos radiculares, que são altamente ativos na síntese e exportação dos compostos, e interagem com muitos organismos incluindo plantas daninhas de outras espécies (Czarnota et al., 2003).

A alelopatia atrai grande interesse das pesquisas agrícolas, pois tem potencial de uso no controle de plantas daninhas na agricultura (Taiz e Zeiger, 2013). Portanto, é possível detectar que a presença de aleloquímicos, originários do metabolismo secundário, possuem alto potencial alelopático sobre distintas espécies. Bem como a alelopatia, a competição entre plantas também é responsável por alterações no metabolismo secundário das espécies.

A competição é um tipo de interferência negativa na qual as plantas competem principalmente por água, luz e nutrientes, e esta altera a composição química das espécies. Normalmente, os parâmetros utilizados para mensurar os efeitos da competição são variáveis morfológicas contudo, poucos são os trabalhos relacionados aos estresses fisiológicos e ao metabolismo secundário das plantas envolvidas na competição (Silva et al., 2014). Atualmente é possível afirmar que há a ativação de mecanismos de defesa quando ocorre competição (Broz et al., 2010; Rivoal et al., 2011; Silva et al., 2014; Gal et al., 2015; Agostinetto et al., 2016). 
A competição pode ocorrer de forma intraespecífica quando ocorrer entre plantas da mesma espécie, e interespecífica quando forem plantas de espécies diferentes. Altas densidades de Pinus halepensis Mill., diminuíram a concentração total de metabólitos secundários, reflexo do crescimento da planta que tende a favorecê-lo em altura, a fim de receber mais luz e de qualidade, induzindo a modificação no metabolismo (Rivoal et al., 2011). Já a competição de arroz cultivado com arroz-vermelho indicou que a planta daninha obteve maior suporte para competir com a cultura, por ter desencadeado o metabolismo secundário com maior produção de compostos fenólicos (Langaro et al., 2011).

O milho em competição com plantas daninhas reduziu o conteúdo de antocianinas no colmo de $0,17 \pm 0,011$ para $0,15 \pm 0,009$,já para o conteúdo de ligninas houve um aumento de 0,86 $\pm 0,105$ para 0,98 $\pm 0,078$ quando em competição (Afifi e Swanton, 2012). A soja competindo com azevém resistente ao herbicida glifosato, alterou o conteúdo de compostos fenólicos totais de 32,47 na proporção de 100:0, para 40,37 na de 50:50, e para $38,53 \mathrm{mg}$ ácido gálico (GAE) $\mathrm{g}^{-1}$ massa fresca (MF) na de 25:75, assegurando a ativação do metabolismo secundário para a defesa da planta quando em competição (Agostinetto et al., 2016).

O mesmo foi observado para a soja competindo com plantas de buva suscetíveis e resistentes ao herbicida glifosato, onde houve aumento do teor de fenóis totais (Silva et al., 2014). Ao competir com azevém, as raízes de plântulas de soja apresentaram diminuição no teor de flavonoides de 3,18 $\mathrm{mg} \mathrm{g}^{-1} \mathrm{MF}$ sem competição, para $2,38 \mathrm{mg} \mathrm{g}^{-1} \mathrm{MF}$ quando em competição (Gal et al., 2015). Pela redução no teor de flavonoides nas raízes de soja, há também a redução no número de nódulos, pois estes compostos são essenciais na sinalização para micróbios simbióticos (Gal et al., 2015), por serem atraentes secretados pelas raízes (Fagan et al., 2007). As plantas têm a capacidade de detectar mudanças na qualidade de luz decorrentes da competição, e sinalizam esta informação para as raízes, alterando a morfologia e constituição bioquímica como estratégia para garantir a sobrevivência (Gal et al., 2015).

Ao reduzir o conteúdo de flavonoides, há a redução das isoflavonas, que são uma classe de flavonoides a qual pertencem a genisteína e a daidzeína, compostos presentes na soja, e que apresentam efeito anticancerígeno (Pereira e Cardoso, 2012). As isoflavonas em soja são sintetizadas como um ramo da via fenilpropanóide, uma rota biossintética secundária em plantas, que pode ser ativada em resposta a estresses bióticos e abióticos (Dixon et al., 2002). Neste sentido, não é de interesse que ocorra essa redução, pois os benefícios do consumo de soja e seus derivados são comprometidos. Para tanto, constituintes do manejo da cultura da soja, como o controle de plantas daninhas, devem ser realizados de maneira eficaz para que não prejudique os benefícios que esta cultura apresenta.

Uma das consequências da competição entre plantas é o aumento da produção de EROs. Estas são produzidas em condições normais do metabolismo celular, no entanto em condições de estresse há o aumento da produção de EROs na célula vegetal (Soares e Machado, 2007; Caverzan et al., 2016). Quando ocorre um aumento na concentração de EROs e um desiquilíbrio nos mecanismos de defesa a célula encontra-se em um estado de estresse oxidativo (Mittler, 2002). Portanto altas concentrações de EROs são extremamente prejudiciais aos organismos, podendo resultar em perdas da capacidade fisiológica e até mesmo morte celular (Caverzan et al., 2016). Entre as principais EROs está o peróxido de hidrogênio, o qual é formado a partir da redução parcial do oxigênio molecular (Mittler, 2002).

A soja ao competir com plantas de azevém aumentou o conteúdo de peróxido de hidrogênio de 0,54 para $0,72 \mathrm{nM} \mathrm{g}^{1}$ (Gal et al., 2015), porém quando em competição com milho, reduziu o teor de peróxido de hidrogênio e aumentou o teor da enzima superóxido dismutase (Piasecki et al., 2017), uma das principais enzimas atuando no controle dos níveis tóxicos de EROs em plantas 
(Caverzan et al., 2016). No milho quando em competição com plantas daninhas, a peroxidação de lipídios aumentou de 0,081 para 0,149 nM (Afifi e Swanton, 2012).

Assim, é possível inferir que a competição entre plantas estimula o metabolismo secundário, e que para a cultura da soja, este estresse é comparável aqueles induzidos por fatores abióticos e bióticos (Agostinetto et al., 2016). Uma abordagem mais ampla do metabolismo secundário das plantas possibilitará a elucidação de rotas metabólicas e genes integrados ao metabolismo, responsáveis pela diversidade química em resposta a problemas genéticos e perturbações ambientais (Chezem e Clay, 2016).

\section{Alterações no metabolismo secundário decorrentes da aplicação de herbicidas}

Uma fonte de alteração no metabolismo secundário das espécies, é ocasionada pela aplicação de herbicidas, pois muitos atuam sobre enzimas que fazem parte de rotas metabólicas de origem a aminoácidos essenciais, como é o exemplo do herbicida glifosato. O glifosato atua sobre a enzima enol-piruvil shiquimato fosfato sintase (EPSPs), que catalisa na planta, a reação que envolve a transferência do enolpiruvil do fosfoenolpiruvato (PEP) para o shikimato-3-fosfato (S3P), formando EPSPs e fosfato inorgânico, levando a síntese dos aminoácidos aromáticos fenilanina, tirosina e triptofano (Velini et al., 2009). Um intermediário desta síntese é a rota do ácido chiquímico, a qual envolve a síntese de antocianinas, flavonoides e isoflavonóides. As antocianinas relacionam-se a expressão de cores relacionadas com insetos benéficos ou prejudiciais às plantas. Os flavonoides são importantes para filtrar e evitar danos provocados por luz ultravioleta. E os isoflavonóides são compostos frequentemente encontrados em leguminosas e com funções na proteção contra insetos e patógenos, e na saúde humana (Velini et al., 2009).
A morte das plantas após a aplicação de glifosato, deve estar associada a três efeitos: a falha na produção de um conjunto de compostos que derivam da rota do ácido chiquímico; ao desregulamento do fluxo de carbono; e à redução da síntese protéica em função da redução das concentrações dos aminoácidos aromáticos (Velini et al., 2009). A aplicação de glifosato resulta em acúmulo de ácido chiquímico pela interrupção da rota de formação dos aminoácidos. Após sete dias da aplicação de glifosato em soja, houve aumento de ácido chiquímico (Franco et al., 2012). Em plantas de ervilha, após a aplicação de glifosato foi encontrado ácido chiquímico, e um rápido acúmulo dos ácidos protocatecuico e gálico, que são formados em ramos laterais da rota do ácido chiquímico, aos três dias e um dia após o tratamento com o herbicida, respectivamente (Orcaray et al., 2010).

A rota octadecanóide é uma via de sinalização em plantas que culmina com a formação do ácido jasmônico, hormônio vegetal que ativa genes de defesa. Como consequência desta rota, também há a formação de peróxido de hidrogênio, que em baixas concentrações está relacionado com a defesa vegetal (Soares e Machado, 2007). As plantas possuem mecanismos de defesa enzimático e não enzimático para controlar os níveis tóxicos de EROs na célula. Entre os enzimáticos encontram-se as enzimas superóxido dismutase, ascorbato peroxidase, glutationa redutase, peroxiredoxina, catalase e polifenol oxidase. Enquanto que glutationa, ácido ascórbico, $\alpha$-tocoferol e carotenoides atuam como antioxidantes não enzimáticos (Mittler, 2002; Caverzan et al., 2016).

A aplicação de herbicidas altera os níveis de peróxido de hidrogênio. Para cultivares de arroz submetidas à diferentes herbicidas houve $\mathrm{o}$ aumento médio de $67 \%$ no nível de peróxido de hidrogênio (Marchezan et al., 2017). Já a exposição das plantas daninhas Leptochloa chinensis e Hedyotis verticillata a aplicação de 2,4-DTBP aumentou as atividades das enzimas superóxido dismutase, peroxidase e catalase, o qual indica 
a indução do mecanismo secundário de defesa (Chuah et al., 2016).

A ativação dos genes de defesa pelas EROs, induz à formação de fitoalexinas, lignina e enzimas hidrolíticas como glucanases e quitinases (Rizzardi et al., 2003). As fitoalexinas são sintetizadas por diferentes vias metabólicas que atuam em conjunto, mas a característica comum da síntese, é a presença da rota do ácido chiquímico (Rizzardi et al., 2003), e sua produção é considerada um dos principais mecanismos de defesa das plantas, estando diretamente associada à prevenção da infecção por muitos patógenos (Taiz e Zeiger, 2013). O herbicida glifosato é um inibidor específico da conversão de chiquimato a corismato, o que leva à redução na biossíntese de fenilalanina e, por conseqüência de fitoalexinas (Rizzardi et al., 2003). Deste modo, é possível observar que a aplicação de herbicidas altera o metabolismo secundário das plantas pela interrupção de rotas importantes na formação dos metabólitos, além de acúmulo de ácidos precursor das rotas. Inúmeros fatores modificam o metabolismo secundário das espécies e estão

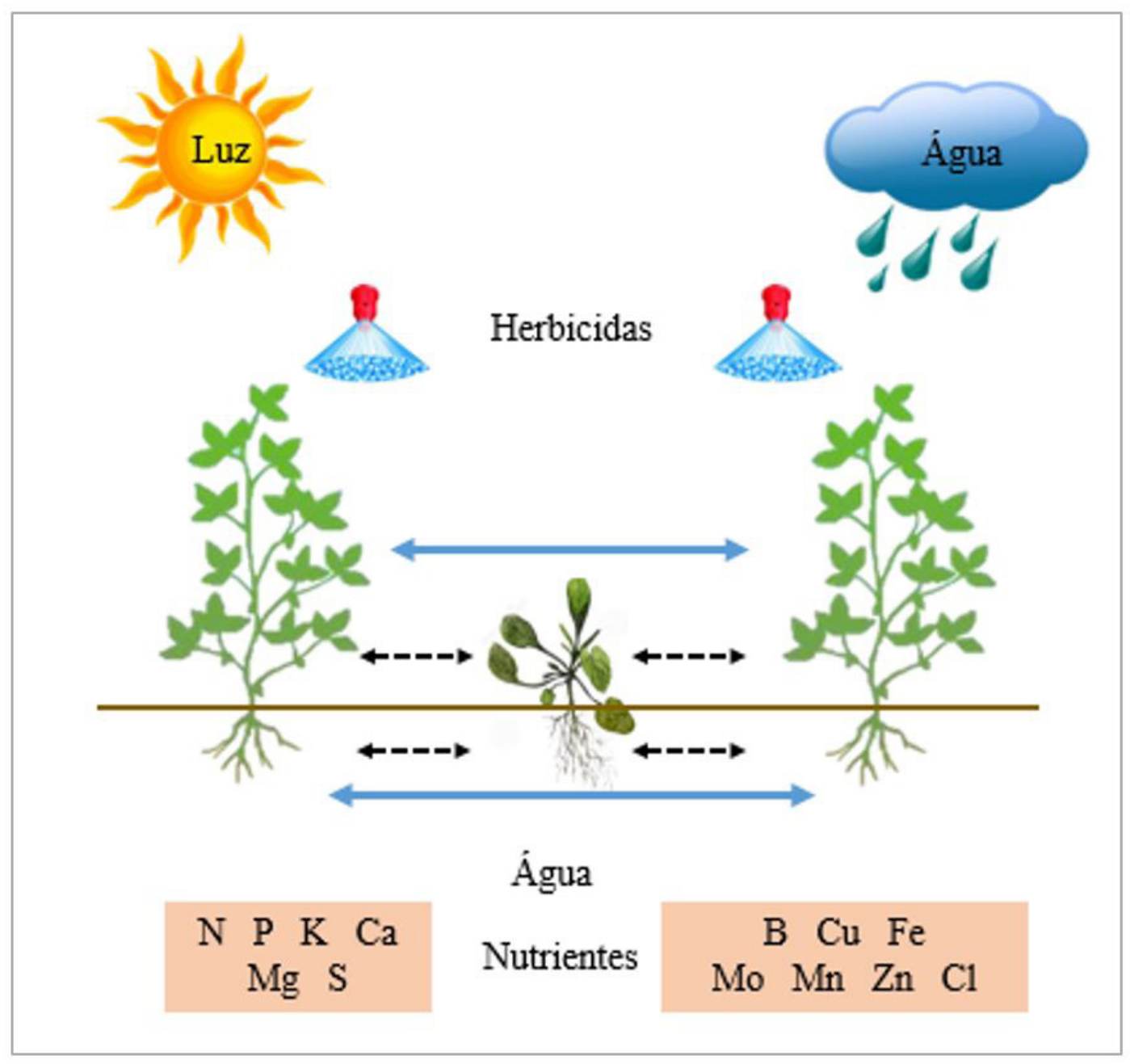

Figura 1. Fatores de alterações no metabolismo secundário das plantas oriundas da interferência com plantas daninhas e da aplicação de herbicidas. Setas azuis indicam interferência intraespecífica, e setas pretas interferência interespecífica. N: nitrogênio; $\mathrm{P}$ : fósforo; $\mathrm{K}$ : potássio; Ca: cálcio; $\mathrm{Mg}$ : magnésio; S: enxofre; B: boro; Cu: cobre; Fe: ferro; Mo: molibdênio; Mn: manganês; Zn: zinco; Cl: cloro. 
diretamente relacionados a presença de plantas daninhas nos cultivos agrícolas (Figura 1).

\section{Conclusão}

Além dos danos conhecidos causados pela competição e pela alelopatia, há um universo de alterações secundárias oriundas destas interferências. A aplicação de herbicidas também torna-se um fator importante nas alterações do metabolismo, pois os locais de atuação destes são também rotas de formação de compostos importantes para o desenvolvimento e sobrevivência das espécies.

\section{Agradecimentos}

Os autores agradecem à Coordenação de Aperfeiçoamento de Pessoal de Nível Superior (CAPES) pelo suporte financeiro. Bolsa PNPD/CAPES de Andréia Caverzan e bolsa Prosup/CAPES de Ana Paula Rockenbach e Theodoro Schneider.

\section{Referências}

Afifi, M.; Swanton, C. Early physiological mechanisms of weed competition. Weed Science, v.60, n.4, p.542-551, 2012.

Agostinetto, D.; Oliveira, C.; Langaro, A.C.; Nohatto, M.A.; Manica-Berto, R. Change in physiological features in ryegrass biotypes in competition with soybean due resistance to glyphosate. Planta Daninha, v.34, n.3, p.517-526, 2016.

Alves, C.C.F.; Alves, J.M.; Silva, T.M.S.; Carvalho, M.G.; Jacob Neto, J. Atividade alelopática de alcaloides glicosilados de Solanum crinitum Lam. Floresta e Ambiente, v.10, n.1, p.93-97, 2003. Broz, A.K.; Broeckling, C.D.; De-La-Pena, C.; Lewis, M.R.; Greene, E.; Callaway, R.M.; et al. Plant neighbor identity influences plant biochemistry and physiology related to defense. BMC Plant Biology, v.10, n.115, p.1-14, 2010.

Caverzan, A.; Casassola, A.; Brammer, S.P. Reactive oxygen species and antioxidant enzymes involved in plant tolerance to stress. In: Shanker, A.K.; Shanker, C. Abiotic and Biotic Stress in Plants - Recent Advances and Future Perspectives. London: InTech, 2016, p.463-480.

Cecchin, K.; Favaretto, A.; Scheffer-Basso, S.M.; Bertol, C.D.; Chini, S.O. Allelopathy and allelochemicals of Eragrotis plana (Poaceae) and its relation with phenology and nitrogen fertilization. Planta Daninha, v.35, p.1-12, 2017.

Chezem, W.R.; Clay, N.K. Regulation of plant secondary metabolism and associated specialized cell development by MYBs and bHLHs. Phytochemistry, v.131, n.1, p.26-43, 2016.

Chuah, T.S.; Norhafizah, M.Z.; Ismal, B.S. Evaluation of the biochemical and physiological activity of the natural compound, 2,4-ditertbutylphenol on weeds. Crop \& Pasture Science, v.66, n.2, p.214-223, 2016.

Cury, J.P.; Santos, J.B.; Silva, E.B.; Byrro, E.C.M.; Braga, R.R.; Carvalho, F.P.; Valadão Silva, D. Acúmulo e partição de nutrientes de cultivares de milho em competição com plantas daninhas. Planta Daninha, v.30, n.2, p.287-296, 2012.

Czarnota, M.A.; Rimando, A.M.; Weston, L.A. Evaluation of root exudates of seven Sorghum accessions. Journal of Chemical Ecology, v.29, n.9, p.2073-2083, 2003.

Dayan, F.E.; Kagan, I.A.; Rimando, A.M. Elucidation of the biosynthetic pathway of the allelochemical sorgoleone using retrobiosynthetic NMR analysis. The Journal of Biological Chemistry, v.278, n.31, p.28607-28611, 2003.

Delory, B.M.; Delaplace, P.; Fauconnier, M.L.; Jardin, P. Root-emitted volatile organic compounds: can they mediate belowground plant-plant interactions? Plant and Soil, v.402, n.1, p.1-26, 2016.

Dixon, R.A.; Achnine, L.; Kota, P.; Liu, C.-J.; Reddy, M.S.S.; Wang, L. The phenylpropanoid pathway and plant defence - a genomics 
perspective. Molecular Plant Pathology, v.3, n.5, p.371-390, 2002.

Fagan, E.B.; Medeiros, S.L.P.; Manfron, P.A.; Casaroli, D.; Simon, J.; Dourado Neto, D.; et al. Fisiologia da fixação biológica do nitrogênio em soja - revisão. Revista da FZVA, v.14, n.1, p.89-106, 2007.

Favaretto, A.; Santos, J.; Carneiro, C.M.; SchefferBasso, S.M.S. The first anatomical and histochemical study of tough lovegrass (Eragrotis plana Nees, Poaceae). African Journal of Agricultural Research, v.10, n.30, p.2940-2947, 2015.

Favaretto, A.; Scheffer-Basso, S.M.; Felini, V.; Zoch, A.N.; Carneiro, C.M. Growth of white clover seedlings treated with aqueous extracts os leaf and root of tough lovegrass. Revista Brasileira de Zootecnia, v.40, n.6, p.1168-1172, 2011.

Ferreira, E.A.; Matos, C.C.; Barbosa, E.A.; Melo, C.A.D.; Silva, D.V.; Santos, J.B. Aspectos fisiológicos de soja transgênica submetida à competição com plantas daninhas. Amazonian Journal of Agricultural and Environmental Sciences, v.58, n.2, p.115-121, 2015.

Fialho, C.M.T.; Silva, G.S.; Faustino, L.A.; de Carvalho, F.P.; Costa, M.D.; da Silva, A.A. Mycorrhizal association in soybean and weeds in competition. Acta Scientiarum, v.38, n.2, p.171-178, 2016.

Fiorenza, M.; Dotto, D.B.; Boligon, A.A.; Boligon, A.A.; Athayde, M.L.; Vestena, S. Análise fitoquímica e atividade alelopática de extratos de Eragrotis plana Nees (capim-annoni). Iheringia, v.71, n.2, p.193-200, 2016.

Franco, D.A.S.; Almeida, S.D.B.; Cerdeira, A.L.; Duke, S.O.; Moraes, R.M.; Lacerda, A.L.S.; Matallo, M.B. Avaliação do uso de glyphosate em soja geneticamente modificada e sua relação com o ácido chiquímico. Planta Daninha, v.30, n.3, p.659-666, 2012.

Gal, J.; Afifi, M.; Lee, E.; Lukens, L.; Swanton, C.J. Detection of neighboring weeds alters soybean seedling roots and nodulation. Weed Science, v.63, n.4, p.888-900, 2015.

Garcia, A.A.; Carril, E.P.-U. Metabolismo secundário de plantas. Reduca (Biologia), v.2, n.3, p.119-145, 2009.

Gobbo-Neto, L.; Lopes, N.P. Plantas medicinais: fatores de influência no conteúdo de metabólitos secundários. Quimica Nova, v.30, n.2, p.374381, 2007.

Green-Tracewicz, E.; Page, E.R.; Swanton, C.J. Light quality and the critical period for weed control in soybean. Weed Science, v.60, n.1, p.86-91, 2012.

Langaro, A.C.; Manica-Berto, R.; Nohatto, M.A.; Rubin, R.S.; Zambiazi, R.C.; Agostinetto, D. Danos celulares em plantas de arroz e capimarroz cultivadas sob condições de competição. In: CONGRESSO BRASILEIRO DO ARROZ IRRIGADO, 7., 2011, Balneário Camboriú. Anais... Porto Alegre: Instituto Rio Grandense do Arroz. p.423-426, 2011.

Li, Y.-H.; Xia, Z.-C.; Kong, C.-H. Allelobiosis in the interference of allelopathic wheat with weeds. Pest Management Science, v.72, n.11, p.2146-2153, 2016.

Lucena, R.B.; Rissi, D.R.; Maia, L.A.; Flores, M.M.; Dantas, A.F.M.; Nobre, V.M.T.; et al. Intoxicação por alcaloides pirrolizidínicos em ruminantes e equinos no Brasil. Pesquisa Veterinária Brasileira, v.30, n.5, p.447-452, 2010.

Marchezan, M.G.; Avila, L.A.; Agostinetto, D.; Schaedler, C.E.; Langaro, A.C.; Oliveira, C.; et al. Morphological and biochemical alterations of paddy rice in response to stress caused by herbicides and total plant submersion. Planta Daninha, v.35, p.1-13, 2017.

Meazza, G.; Scheffler, B.E.; Tellez, M.R.; Rimando, A.M.; Nanayakkara, N.P.D.; Khan, I.A.; et al. The inhibitory activity of natural products on plant p-hydroxyphenylpyruvate dioxygenase. Phytochemistry, v.60, n.3, p.281-288, 2002. 
Medeiros, W.N.; Melo, C.A.D.; Tiburcio, R.A.S.; Silva, G.S.; Machado, A.F.L.; Santos, L.D.T.; Ferreira, F.A. Crescimento inicial e concentração de nutrientes em clones de Eucalyptus urophylla $\mathrm{x}$ Eucalyptus grandis sob interferência de plantas daninhas. Ciência Florestal, v.26, n.1, p.147157, 2016.

Metlen, K.L.; Aschehoug, E.T.; Callaway, R.M. Plant behavioural ecology: dynamic plasticity in secondary metabolites. Plant, Cell \& Environment, v.32, n.6, p.641-653, 2008.

Mittler, R. Oxidative stress, antioxidants and stress tolerance. Trends in Plant Science, v.7, n.9, p.405-410, 2002.

Orcaray, L.; Igal, M.; Marino, D.; Zabalza, A.; Royuela, M. The possible role of quinate in themode of action of glyphosate and acetolactate synthase inhibitors. Pest Management Science, v.66, n.3, p.262-269, 2010.

Pereira, R.J.; Cardoso, M.G. Metabólitos secundários vegetais e benefícios antioxidantes. Journal of Biotechnology and Biodiversity, v.3, n.4, p.146-152, 2012.

Piasecki, C.; Rizzardi, M.A.; Schons, J.; Caverzan, A.; Chavarria, G. A competição de populações de milho voluntário $R R \circledast$ causa estresse oxidativo em soja? Planta Daninha, 2017. No prelo.

Radosevich, S.R.; Holt, J.S.; Ghersa, C.M. Ecology of weeds and invasive plants: relationship to agriculture and natural resource management. 3.ed. New York: Willey, 2007. 589p.

Rechner, O.; Neugart, S.; Schreiner, M.; Wu, S.; Poehling, H.M. Different narrow-band light ranges alter plant secondary metabolism and plant defense response to aphids. Journal of Chemical Ecology, v.42, n.10, p.1-15, 2016.

Rivoal, A.; Fernandez, C.; Greff, S.; Montes, N.; Vila, B. Does competition stress decrease allelopathic potential? Biochemical Systematics and Ecology, v.39, n.4, p.401-407, 2011.
Rizzardi, M.A.; Fleck, N.G.; Agostinetto, D.; Balbinot Junior, A.A. Ação dos herbicidas sobre mecanismos de defesa das plantas aos patógenos. Ciência Rural, v.33, n.5, p.957-965, 2003.

Sampaio, B.L.; Bara, M.T.F.; Ferri, P.H.; Santos, S.C.; Paula, J.R. Influence of environmental factors on the concentration of phenolic compounds in leaves of Lafoensia pacari. Revista Brasileira de Farmacognosia, v.21, n.6, p.1127-1137, 2011. Sampaio, B.L.; Edrada-Ebel, R.A.; Costa, F.B. Effect of the environment on the secondary metabolic profile of Tithonia diversifolia: a model for environmental metabolomics of plants. Scientific Reports, v.6, n.29265, p.1-14, 2016.

Santos, I.L.V.L.; Silva, C.R.C.; Santos, S.L.; Maia, M.M.D. Sorgoleone: benzoquinona lipídica de sorgo com efeitos alelopáticos na agricultura como herbicida. Arquivo Instituto Biológico, v.79, n.1, p.135-144, 2012.

Selmar, D.; Kleinwächter, M. Influencing the product quality by deliberately applying drought stress during the cultivation of medicinal plants. Industrial Crops and Products, v.42, n.1, p.558566, 2013.

Shah, A.N.; Iqbal, J.; Ullah, A.; Yang, G.; Yousaf, M.; Fahad, S.; et al. Allelopathic potential of oil seed crops in production of crops: a review. Environmental Science and Pollution Research International, v.23, n.15, p.14854-14867, 2016.

Silva, D.R.O.; Agostinetto, D.; Vargas, L.; Langaro, A.C.; Duarte, T.V. Habilidade competitiva, alterações no metabolismo secundário e danos celulares de soja competindo com Conyza bonariensis resistente e suscetível a glyphosate. Planta Daninha, v.32, n.3, p.579-589, 2014.

Silva, M.L.C.; Costa, R.S.; Santana, A.S.; Koblitz, M.G.B. Compostos fenólicos carotenoides e atividade antioxidante em produtos vegetais. Semina Ciências Agrárias, v.31, n.3, p.669682, 2010. 
Soares, A.M.S.; Machado, O.L.T. Defesa de plantas: sinalização química e espécies reativas de oxigênio. Revista Trópica - Ciências Agrárias e Biológicas, v.1, n.1, p.9-19, 2007.

Taiz, L.; Zeiger, E. Fisiologia vegetal. 5.ed. Porto Alegre: Artmed, 2013.

Teofilo, T.M.S.; Freitas, F.C.L.; Medeiros, J.F.; Fernandes, D.; Grangeiro, L.C.; Tomaz, H.V.Q.; Rodrigues, A.P.M.S. Eficiência no uso da água e interferência de plantas daninhas no meloeiro cultivado nos sistemas de plantio direto e convencional. Planta Daninha, v.30, n.3, p.547$556,2012$.

Velini, E.D.; Duke, S.O.; Trindade, M.L.B.; Meschede, D.K.; Carbonari, C.C. Modo de ação do glyphosate. In: Velini, E.D.; Meschede, D.K.; Carbonari, C.A.; Trindade, M.L.B. Glyphosate. Botucatu: Fepaf, 2009, cap. 5, p.113-133.

Viegas-Junior, C.; Bolzani, V.S.; Barreiro, E.J. Os produtos naturais e a química medicinal moderna. Quimica Nova, v.29, n.2, p.326-337, 2006. 